\title{
Pharmaceutical Clusters: Remedy for Regional Economies
}

\author{
Elena Novoselova
}

The idea of pharmaceutical clusters is being actively pursued in Russia. Several projects have already been implemented, while others are in the pipeline. There are optimistic reports about regions setting up manufacturing, improving the level of education, and creating jobs, and about pharmaceutical companies receiving infrastructure and tax incentives. Is there reason to expect innovation with pharmaceutical clusters as well? That issue, along with others, was taken up at the International Forum "Innovative Drug Research and Development in Russia" organized by the Adam Smith Institute on November 17-18, 2010, in Moscow.

A cluster is a voluntary regional industrial association of businesses in active collaboration with research and social institutions and local governments, aimed at making their products more competitive and promoting economic development in the region.

More and more such clusters are currently being created in Russia in mechanical engineering, metal works, aerospace engineering, shipbuilding, IT, optoelectronics, instrument engineering, wood processing, agriculture and the agro industry, pharmaceuticals, etc. The creation of pharmaceutical clusters has been announced in St. Petersburg, Moscow and the Moscow region, Yaroslavl, Kaluga and the Sverdlovsk regions, Siberia, Stavropol Territory, and Tatarstan.

The effort continues to face a number of issues on this path: are the regions ready for pharmaceutical clusters? Will they be able to find companies willing to settle in the clusters? What kind of production should be developed (own brands of drugs, generics, or simply drug packaging)? How to lead innovative research and educational programmes? Will the pharmaceutical clusters help replace imported drugs? What is the legal framework? How will the efficiency of the cluster be assessed? And how many pharmaceutical clusters does Russia need?

The idea is that the entire chain of drug development and production will be implemented on the ter- ritory of a pharmaceutical cluster. Only few regions can claim to have created full-cycle clusters, including personnel training, research and development (R\&D), and manufacturing. In Russia, it is rather more accurate to speak of the existence of special economic zones, which attract drugs manufacturers by the attractiveness of their pharmaceutical markets (which continued to grow even during the recent crisis) and active government support (the Pharma-2020 Strategy).

Apparently, Russia does not have enough companies to populate the mooted pharmaceutical clusters. In addition, attracting foreign companies is important for technology transfer and personnel training in drug manufacturing, as well as R\&D. However, it is encouraging that big international pharmaceutical companies have joined the pharmaceutical clusters project. The Yaroslavl cluster for the pharmaceutical industry and innovative medicine meets all the criteria for a pharmaceutical cluster, and it has already attracted some serious players. One of the residents of that pharmaceutical cluster is the Swiss drug maker Novartis Pharma. On 7 September 2010, Hari Swen Krishnan, Director of Novartis Pharma Russia, and Sergey Vakhrukov, governor of Yaroslavl region, signed a Memorandum of Understanding between the Government of Yaroslavl region and Novartis Pharma for cooperation in healthcare and medical science. According to the Memoran- dum, the two main thrust of the cooperation will be to provide additional personnel development in healthcare and carry out research in innovative drugs, particularly including staff training for carrying out more clinical tests. In 2011, Novartis Pharma plans to create a Centre for Clinical Studies at Yaroslavl State Medical Academy. The collaboration in clinical research has been ongoing in the Yaroslavl region for 7 years; leading academic institutions and hospitals in the region, in partnership with Novartis Pharma, have participated in 17 international clinical studies of 14 parameters.

An inter-institutional research and educational innovative center connecting leading educational institutions is under development in the region. It will provide specialists for innovative R\&D in pharmacology and medicine. In addition, special personnel training programmes for pharmaceutical companies are being set up at educational institutions. For instance, Novartis Pharma has started a joint educational programme with Yaroslavl State Medical Academy comprising special personnel training modules in medicine and pharmaceuticals with internships at the company's plants, as well as teaching staff training modules. Nycomed, together with Yaroslavl State Medical Academy and Yaroslavl Technical University, based at the Chemical Engineering school, has launched a technical personnel-training programme for the 
pharmaceutical industry. On September 1, 2010, the first group of 25 students began studies in 3 professional programmes.

In June 2010, Nycomed also started construction of a plant in the Yaroslavl region for manufacturing drugs for the treatment and prevention of neurological and cardiological diseases. The company has invested 75 million euro in the construction and plans to begin production as early as 2014. R-Pharm and ChemRar hightech Centers have announced the construction of a plant for producing drug active ingredients in Yaroslavl region. The project, known as Pharmoslavl, is aimed at making healthcare in Russia less dependent not only on the import of drugs, but also on the import of drug ingredients.

The first production of nanotechnological flu vaccines in Russia will begin at the Yaroslavl pharmaceutical cluster, with Rusnano and NT Pharma Ltd. as investors. The creation of the new entity, NT Pharma, instead of investment in the existing Immapharma, helped streamline financial audit and ensure Rusnano's $49 \%$ participation in the project. Rusnano has invested 1.5 billion rubles initially, and additional funding will be obtained by reinvesting part of the profits from swine flu nanovaccine sales.

The Kaluga pharmaceutical cluster is another example of a regional association of educational, research, and industrial organisations in pharmaceutics.

In 2006, Hemofarm, a member of the German STADA group, built a plant in the city of Obninsk (Kaluga region) with maximum annual capacity of 2.5 billion tablets, with 32 million euro invested in construction. Novo Nordisk has announced the construction of an insulin plant in the region. According to the Memorandum of Intent between Novo Nordisk and the government of Kaluga region, $\$ 80-100$ million will be invested in construction. The agreement sets the partners' responsibilities for cre- ating the necessary infrastructure (power, gas, water supply, roads, etc.) and provides general guidelines for land lot purchase. Berlin-Chemie AG, a member of the Menarini Group, has also signed an agreement on establishing production in Kaluga region. In the first stage of the project, with an investment of 30 million Euro, a packaging line will begin operating in Kaluga in 2013, and drug production will begin in 2014 .

In September 2010, two Russian pharmaceutical companies, PharmSynthesis and NIARMEDIC PLUS, announced plans to establish production in Kaluga region. PharmSynthesis will build a full-cycle production and packaging facility for oncological drugs and diagnostic products made from proprietary ingredients. The project is scheduled for completion in summer 2011. The company will invest about 10 million Euro by 2012. NIARMEDIC PLUS will create a full-cycle production facility for the company's two key products: an antiviral interferon inducer and a collagen material used in surgery, trauma treatment, and orthopaedic care.

The Russian venture company Seed Fund is invested in shaping the pharmaceutical cluster of the Kaluga region. The Fund has committed its first investment into local projects proposed by the regional enterprises: the Cardiomarker myocardial infarction diagnostic system (Obninsk Pharmaceutical Company Ltd.) and a renal carcinoma drug (OncoMax Ltd.).

For the move from industrial parks to regional clusters to be successful, designing educational programs, training personnel, localizing $\mathrm{R} \& \mathrm{D}$ in the cluster region, and creating clinical test centres are very important. Thus, a few years ago, in the framework of the Kaluga region pharmaceutical cluster, a Department of Medicine was established at Obninsk State Technical University of Nuclear Energy (subsidiary of the National Research Nuclear University MEPHI).
A personnel training centre for the pharmaceutical industry has been created in the Kaluga region in collaboration with the Berlin Centre of Professional Training, a center that specializes in the pharmaceutical and chemical industries, as well as with People's Friendship University of Russia and the International Pharmaceutical Federation. On September 1, 2011, 300 students will begin studying in more than 20 educational programmes.

In his speech at the "Innovative Drug Research and Development in Russia" forum, Ruslan A. Zalivatskiy, the minister of economic development of Kaluga region, said that the Kaluga region government had created all necessary conditions for the success of investment projects. Thus, the industrial parks created provide companies with a complete engineering and logistic infrastructure; there are land plots for lease and sale, as well as ready-to-use production facilities available for long-term lease. This philosophy of the regional government has already yielded 56 active investment projects, with 5 more that were to be launched by the end of 2010.

On April 22, 2010, the St. Petersburg region government approved the concept of the St. Petersburg pharmaceutical cluster. St. Petersburg has all that is needed for a successful development of an innovative pharmaceutical industry: scientific and production staff, research institutes, drug developers, 11 academic institutions specialized in chemistry and medicine, and a broad clinical base. Currently, a dozen large and middle-size enterprises manufacture a wide range of drugs in St. Petersburg. Valentina Matvienko, the mayor of the St. Petersburg region, says that pharmaceutical projects will become a priority for the city's economy and will be supported by the government. An inter-institutional research centre incorporating the St. Petersburg State University of Technology, Pavlov St. Peters- 
burg Medical University, and the St. Petersburg State Chemical-Pharmaceutical Academy was created to coordinate implementation of the concept.

The shaping of the St. Petersburg pharmaceutical cluster began with the creation of the Neudorf special economic zone; the Novoorlovskaya special economic zone will follow, and then the Pushkinskaya industrial zone. The first enterprises to join the new cluster were the Russian companies Geropharm Ltd. (injection drugs, up to 55 million vials, 1.3 billion rubles invested), Biocad (original and copied oncological, neurological, urological, and gynaecological drugs, 1.07 billion rubles invested), Neon Ltd. (medical and pharmaceutical equipment, pharmaceuticals, 910 million rubles invested), and Samson-Med Ltd. (drugs based on natural active ingredients, 1.5 billion rubles invested).

On October 27, 2010, the St. Petersburg Legislature approved a draft law On Amendments to the St. Petersburg Law On Tax Exemptions. The profit tax rate for investors will be reduced to $13.5 \%$, and investors will be exempt from property tax. Until now, the profit tax rate, which varied depending on the invested amount, could reach up to
$15.5 \%$. In addition, the new law sets the uniform threshold investment for an organization to qualify for tax exemptions at 800 million rubles. Under existing legislation, only organizations investing 3 billion rubles and more can enjoy the $13.5 \%$ profit tax rate. The new law also extends the exemption term from 3 to 5 years; at the same time, the investor will now have to invest funds during 3 years, instead of 1 , as is the case now. The law also sets some requirements for investors in the high-tech sector. For example, profit tax deductions start at a 50-million-ruble investment.

These are just a few examples of the implementation of the pharmaceutical cluster concept. Will the clusters meet the expectations of business, the state, and regional players, and how will one be able to assess the efficiency of a cluster? Should one rely on the number of participants (plants and research centres), the number of registered and produced drugs, the amount of money invested, or annual production volumes?

Regional governments are striving to create a favourable investment climate in the clusters, not only for manufacturing but also to spur innovation. The federal government supports the idea of creating pharmaceutical clusters, since the clusters are seen both as a tool for an innovative economy and for addressing social issues such as unemployment and education. Naturally, the legal landscape needs adjustment to facilitate the trend. The companies involved in pharmaceutical clusters argue for organizing an Association of Russian Pharmaceutical Clusters, in order to lobby the interests of those in the clusters. In October 2010, the Committee on Entrepreneurship in the Healthcare Industry at the Chamber of Commerce and Industry proposed the idea of preparing an independent Development Concept of pharmaceutical clusters in Russia. Following the initiative, a workgroup will be created with the participation of representatives of the ministries of Economic Development, Industrial Trade, Healthcare and Social Development, the Russian Patent Bureau, as well as other agencies, regional governments, the scientific community, entrepreneurs associations, and the business community. The Committee also recommended that the Chamber propose that the Federal Government create a special chapter called Development of Pharmaceutical Clusters in Russia in the Federal target programme Development of the Pharmaceutical and Medical industries in Russia until 2020.

\section{COMMENT}

Victor Dmitriev, Director General, Association of Russian Pharmaceuticals Manufacturers

Many regions have announced the creation of pharmaceutical clusters. However, we have no legal definition of what a cluster is.

Regarding the Association of Russian Pharmaceutical Clusters, the Association of Russian Pharmaceuticals Manufactur-

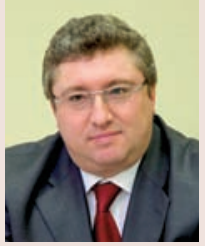
ers is not against the idea, but the goal should be made clear. Associations are formed in order to resolve certain issues and lobby interests.
Moreover, some do not understand what the purpose of building a cluster in the region is. Is it to create jobs, develop the pharmaceutical industry, and provide people with affordable drugs? Otherwise, to promote scientific development and create innovative drugs? Or perhaps to further someone's political ambition? Indeed, the purposes of a pharmaceutical cluster should be in line with government contracts. This means that the pharmaceutical clusters should lead to lower diseases and death rate, a higher quality of life-these are the main indices of health care.

I can point to a couple of promising projects with clear goals, scientific po- tential, a manufacturing base, qualified personnel, good infrastructure, investors, etc. With such inputs a pharmaceutical cluster will really be able to function properly. Thus, St. Petersburg is perfectly positioned to make a pharmaceutical cluster a success. They have scientific potential, educational facilities, manufacturing capabilities, companies willing to invest in pharmaceutical production, and investors. The level of scientific development in St. Petersburg makes me hopeful that the cluster will pursue innovation and not follow in someone else's steps. Everything is ready for the creation of new drugs. Yaroslavl and Kaluga are other good examples. 